\title{
Cadaveric Temporal Bone Dissection Workshop in a Tertiary ENT- HNS Centre: Is Our Teaching Satisfactory?
}

\author{
Pabina Rayamajhi, Susmita Shrestha, Rabindra B Pradhananga and Hari Bhattarai
}

Department ENT and HNS, Institute of Medicine, Tribhuvan University Teaching Hospital, Maharajgunj, Kathmandu, Nepal

\begin{abstract}
Introduction: Teaching learning skills are developed through various skill lab procedures. In the Department of ENT and HNS, Temporal Bone Dissection (TBD) is one of the methods of teaching. The TBD workshop conducted in the Department caters to most of the postgraduate students in the country. This study was conducted in the Department of ENT and HNS to evaluate the participants' satisfaction on TBD course conducted in the Department.

Methods: The TBD participants who had undergone TBD course in the Department of ENT and HNS were asked to fill up the questionnaire regarding the satisfaction of the TBD course and suggestions for the improvement of the course. The participants provided the response of the questionnaire in the email or in hand filling of the forms.

Results: Total of 42 students responded to the questionnaire regarding the TBD course. $88 \%$ of the students graded it as good, $11 \%$ replied as satisfactory and $1 \%$ of them graded it as needs improvement. Maximum number of students commented on the inadequate time for dissection. Few participants replied the need of live demonstration in the course. $9.5 \%$ of the participants who had come for the course more than once commented on the great help done by the course in performing live otology surgery.

Conclusions: Maximum participants were satisfied about the TBD workshop which helped them to know the intricate temporal bone anatomy.

Key words: otology; questionnaire; Temporal Bone Dissection (TBD)
\end{abstract}

Correspondence: Susmita Shrestha, Department of ENT-HNS, Institute of Medicine, Tribhuvan University Teaching Hospital, Maharajgunj, Kathmandu, Nepal. E-mail: sushmitaiom@gmail.com.

DOI: http://dx.doi.org/10.3126/mjsbh.v19i1.26489

Submitted on: 2019-11-06

Accepted on: 2019-12-10 


\section{INTRODUCTION}

Skill lab training is upcoming as one of the modalities of training doctors and preparing them for dealing with the real-life situation. In the field of ENT-HNS, Temporal Bone Dissection (TBD) is one of the training methods for teaching the anatomy of ear as well getting them acquainted with the live surgery as well. Temporal bone is one of the very complex and fascinating anatomical structure in human body. Use of cadaveric temporal bone for dissection to learn the intricate anatomy of temporal bone bears a long history. Repeated dissection of the temporal bone is an essential way to learn the anatomy of the temporal bone and master ones' surgical skills as well. ${ }^{1}$

Use of microscope is essential in the Otology surgery. Microscopic ear surgery has a learning curve which is mastered slowly. For beginners it is always a challenge to maintain the hand and eye coordination in microscopic ear surgery. Residents and trainee doctors need to spend ample amount of time in temporal bone dissections in learning the anatomy, develop the motor skills and hand-eye coordination on using the microscope. ${ }^{1}$ Dissection in the temporal bone is always of a great help in learning the otology surgery.

TBD workshop is run worldwide with good opportunity for junior doctors to learn and master their otology micro ear surgery. Some places are now having shortage of wet bones for dissection. Also, there is a growing concern on the rights of the cadavers and thus leading to the difficulty in managing the temporal bones. ${ }^{2}$

TBD course is being conducted in our department for nearly twenty years and is the only hospital in the whole country to run the TBD workshop. This makes it more demanding to accommodate the increasing number of resident and junior doctors. Like every course and workshops which improves and evolves with increasing number of courses conducted, our course has also gone through minor changes. These changes are mainly after the feedback taken from the students who are the best critics. This study aims to study on the feedback of the course from the participants on their satisfaction and to analyse their suggestions.

\section{METHODS}

This retrospective questionnaire-based was conducted in the department of ENT and Head \& Neck Surgery, Maharajgunj Medical Campus, Institute of Medicine. This is a retrospective data collection done from the participants of the TBD workshops from September 2016 to October 2019. The TBD workshop is being run in the Department with the help from the Forensic Medicine Department since the last twenty years. The workshop is conducted for three days from 8 am to $5 \mathrm{pm}$ in a structured format. There are eight tables for dissectors thus the course accommodates sixteen hands-on residents. First two hours every day is the demonstration by the faculty to the whole group. Then the participants are divided into two groups; first group in the dissection and the second group in the video or lecture session. Each participant gets one table with temporal bone for dissection. Each of them is provided with the set of instruments, suction unit, stand for fixing the temporal bone and microscope. The session changes in the second half of the workshop. There are faculties as facilitators during the dissections. All the bones provided are the wet bones preserved in formalin. They were provided with the diagrammatical instructional manual too that guided them to plan their dissection steps. Since this was a basic TBD course, the steps they followed were the myringotomy with grommet insertion, cortical mastoidectomy, stapedotomy, posterior tympanotomy, facial nerve decompression and modified radical mastoidectomy. If they had time and could proceed, they were allowed to perform labyrinthectomy, endolymphatic decompression, assessment of internal auditory canal, jugular and carotid artery course too.

The video session included mainly the common ear surgeries done in the Department or outside like myringoplasty, modified radical mastoidectomy, stapedotomy or cochlear implantation. Sometimes lectures were held discussing the temporal bone radiology, common things to remember while doing 
ear surgery, stapedotomy, endoscopic ear surgeries etc.

For this study, at the end of the programme, the participants were provided with the questionnaire to write about the feedback and their suggestions for the improvement of the course. The participants who missed filling the questionnaire were sent the questionnaire and replied via their emails. The answers, suggestions were tabulated and analysed.

The questionnaires listed were:

1. Was it your first TBD workshop or more than once?

2. Was the workshop useful?

3. Did the workshop improve your temporal bone anatomical knowledge?

4. Was the temporal bone fine (well preserved) for you?

5. How were the faculties?

6. What were the weak points of the course?

7. What advises to improve the course further?

\section{RESULTS}

We have assessed responses on the questionnaire from 42 participants. The responses to first few questionnaires were as shown in Table 1. 38 (90.5\%) of them had their first time TBD workshop participation. Remaining $9.5 \%$ of the participators had previously done temporal bone dissection multiple as referred in the above Table 1. Each dissection had added on to their knowledge and skills both during multiple dissections. All the participants responded that the dissection was very useful. The main advantage was the single temporal bone that they were able to dissect through three days. The workshop improved their anatomical knowledge about their temporal bone. Since most of them were residents and junior doctors knowing once again the facial nerve anatomy was a great advantage. Most of them had started performing their mastoid surgery and getting used to the burrs, knowing the facial nerve course, the ossicles, tip cells, digastric ridge etc. were a great help. Those who had previously participated in the workshop had stated that the temporal bone dissection had improved their hand and eye coordination in their MJSBH Vol 19 Issue 1 Jan-Jun 2020
Table 1. Responses to the TBD questionnaires

\begin{tabular}{|c|c|c|c|}
\hline SN & Question & Yes & No \\
\hline 1 & $\begin{array}{l}\text { Was it your first TBD } \\
\text { workshop? }\end{array}$ & $90.5 \%$ & $9.5 \%$ \\
\hline 2 & Was the workshop useful? & $100 \%$ & $0 \%$ \\
\hline 3 & $\begin{array}{l}\text { Did the workshop improve } \\
\text { your temporal bone } \\
\text { anatomical knowledge? }\end{array}$ & $100 \%$ & $0 \%$ \\
\hline 4 & $\begin{array}{l}\text { Was the temporal bone fine } \\
\text { (well preserved) for you? }\end{array}$ & $90.5 \%$ & $9.5 \%$ \\
\hline
\end{tabular}

microscopic ear surgery, improved their drilling skill and helped them judge their facial nerve location and depth. To the response regarding the temporal bone status; four of them were not satisfied about their temporal bone. The temporal bone was contracted in three, one of them had central perforation with absence of incus and one was a sclerosed bone.

Regarding the faculties the participants were satisfied. They felt that they were easily approachable. The participants enjoyed the demonstration session and could easily follow in their temporal bone too. They found the programme well structured.

On further evaluation of the remarks of the participators, regarding the weak points in the course that needed improvement were as shown in Table 2.

Twenty-four participants felt that the videos were not updated as shown in Table 2. They suggested the need to update the videos and put videos of difficult cochlear implantation, facial nerve decompression and lateral skull base surgery. The dissection duration was felt to be less by maximum number of students with suggestion to keep the video session less and dissection session more.

Table 2. Points to improve during the course

\begin{tabular}{|l|l|c|}
\hline SN & Questions & Response \\
\hline 1 & The videos were not updated & $57.1 \%$ \\
\hline 2 & $\begin{array}{l}\text { The videos were of poorer } \\
\text { quality }\end{array}$ & $55 \%$ \\
\hline 3 & \begin{tabular}{l} 
The dissection duration less \\
\hline
\end{tabular} & $90.5 \%$ \\
\hline
\end{tabular}


Table 3. Suggestions to improve the course

\begin{tabular}{|l|l|l|}
\hline SN & Suggestions & Response \\
\hline 1 & Frequent TBD courses & $76.2 \%$ \\
\hline 2 & $\begin{array}{l}\text { Addition of live surgical } \\
\text { demonstration }\end{array}$ & $66.7 \%$ \\
\hline 3 & $\begin{array}{l}\text { More dissection tables } \\
\text { Provision of multiple cadaveric } \\
\text { bones }\end{array}$ & \begin{tabular}{l}
$71.4 \%$ \\
\hline 4
\end{tabular} \\
\hline 5 & $\begin{array}{l}\text { External faculties participation } \\
\text { Advance temporal bone } \\
\text { dissection }\end{array}$ & $28.6 \%$ \\
\hline 6 & $23.8 \%$ \\
\hline
\end{tabular}

Some of the suggestions were to keep the course of four days.

As mentioned in above Table 3, majority of the participants felt the need to increase the frequency of the TBD course as our institution is the only one to conduct the course in the whole country. Due to the increasing number of residents and junior doctors there is a need to have multiple courses or courses to be conducted in other centres as well. Addition of multiple bones for dissection were suggested by some where we have been providing one additional bone but due to the limited time most of the participants were able to manage dissection of only one bone. The external faculties involvement was though suggested could be managed five times in the last 25 courses. The advance temporal bone has been planned in future with the availability of the external faculty.

\section{DISCUSSION}

Medical teaching has been evolving for many years. Among the various ways of skill learning in Otorhinolaryngology; temporal bone dissection is one of them. It is very important for all ENT doctors to keep practicing on temporal bone dissection to uplift their skills on temporal bone. ${ }^{3}$

Our study mentions the importance of cadaveric temporal bone dissection for students and junior doctors to improve their temporal bone anatomy. There is a growing need of the temporal bone dissection as a learning skill tool for ear surgery. Likewise, Feigl et al. ${ }^{3}$ in his study of cadaveric temporal bone dissection mentioned a significant MJSBH Vol 19 Issue 1 Jan-Jun 2020 improvement in the anatomical knowledge and skill of performing specific surgeries after repeated cadaveric dissections.

Naik et al. ${ }^{2}$ and Ajita et al. ${ }^{4}$ also mentioned the importance of temporal bone drilling to master the anatomy of temporal bone and learning ear surgery. Fennessy et al. ${ }^{5}$ also stated the importance of temporal bone dissection to understand the core anatomy and learning the safe ontological skills.

Adoga et al. at university of Jos, Nigeria had conducted a study on the temporal bone dissection of 18 bones, practicing for cochlear implantation and mastoid surgery. They stressed on the fact the importance of the fresh cadaver during dissection for surgical training. ${ }^{6}$ Our institute does not have the provision of providing fresh bones.

Though there are various methods apart from cadaveric dissection for teaching human anatomy, George et al. ${ }^{7}$ emphasises on the importance of temporal bone dissection on learning. They stressed on the fact that the temporal bones are the best for learning the anatomical variations.

The temporal bones used in our TBD course is provided by the Department of Forensic Medicine. They are preserved in formalin till the dissection time. This is the only institute in the whole country managing the TBD course. As there is a dearth of temporal bones the course is on demand. Till now procurement of temporal bone is not so difficult but in future due to the growing consciousness on the cadaveric rights, it might be difficult for the supply of the temporal bones. In many centres around the world controversies regarding organ retention have resulted in a more limited supply of temporal bones. Even in our neighbouring country India, the Anatomy Act of each state provides for the supply of unclaimed bodies to the medical and teaching institutions for the purpose of anatomical dissection. $^{8}$

In our course the temporal bones used are preserved in formalin. This is better than dry bones as they retain the anatomical structures. Fresh cadaveric bones for dissection are difficult to obtain in our centre. 
Due to the rising difficulty in the cadaveric temporal bones few centres have opted for the use of other educational tools like three-dimensional computer models for teaching. Wiet et al. ${ }^{9,10}$ have performed pioneering research in developing surgical simulator for temporal bone surgery. They have combined the imaging data with the computer technology to create simulation environments to mimic reality. Okada et al. ${ }^{11}$ constructed an artificial temporal bone by molding silicone and acrylic to make a porous material which is similar to the pneumatisation of the mastoid. This can be used in the teaching purposes.

Thus, at present, plastic models, porcine dissection and virtual reality temporal bone simulators are the alternatives to cadaveric temporal bone dissection. ${ }^{12}$ Though all different techniques are well documented in the literature; cadaveric dissection is always a standard. Our centre too runs only the cadaveric dissection as we haven't still developed other alternatives. Though the course has been running for nearly 25 times there is still a scope to develop more.

On analysing our course based on the participants response, there is a need to update the videos and improve the quality of the videos as well. Though there are suggestions to increase the duration of the dissection we feel that the basic course timing is sufficient. It's always better to repeat the course to master the otology skills. There is a need to develop this course in other centres in the country too so that the junior faculties and resident doctors can have more exposure. The need for external faculty is felt more for the advance course which is needed more for the senior faculties thus not done in a regular basis.

As per the suggestions to increase the dissection tables and the advance courses; we would look in the matters in the future. There is a scope to develop the temporal bone laboratory in future too. In many centres around the world there is fixed set of temporal bone lab in the institute. This being one of the costly setups is difficult in our part of the world.

\section{CONCLUSIONS}

The temporal bone dissection course run in our institute appears to be satisfactory as more than $90 \%$ of the students have found it to be useful. There are scopes to improve like the addition of recent, updated videos and organising more frequent workshops.

To cite this article: Rayamajhi $\mathrm{P}$, Shrestha S, Pradhananga RB, Bhattarai H. Cadaveric Temporal Bone Dissection workshop in a tertiary ENT- HNS centre: is our teaching satisfactory? MJSBH. 2019;19(1):10-5.

Conflict of Interest: None declared

\section{REFERENCES}

1. George AP, E RD. Review of temporal bone dissection teaching: how it was, is and will be. J Laryngol Otol. 2010;124:119-25.

DOI: https://doi.org/10.1017/S0022215109991617

2. Naik SM, Naik MS, Bains NK. Cadaveric temporal bone dissection: Is it obsolete today? Int Arch Otorhinolaryngol 2014;18:63-7.

DOI: https://doi.org/10.1055/s-0033-1351681

3. Feigl G, Kos I, Anderhuber F, Guyot JP, Fasel J. Development of surgical skill with singular neurectomy using human cadaveric temporal bones. Ann Anat. 2008;190:316-23.

DOI: https://doi.org/10.1016/j.aanat.2008.05.001 
4. Ajita R, Singh YI. Body donation and its relevance in anatomy learning: a review. J Anat Soc India. 2007;56(1): 44-4.

5. Fennessy BG, O'Sullivan P. Establishing a temporal bone laboratory: considerations for ENT specialist training. Ir J Med Sci. 2009;178:393-5. DOI: https://doi.org/10.1007/s11845-009-0373-x

6. Adoga SA, Maan ND, Umar BT, Benjamin TU, Nwaorgu GO. Cadaver temporal bone dissection: the JOS experience. Webmed Central Otorhinolaryngology. 2011;2:WMC001767.

Available at: http://www.webmedcentral.com/article_view/1767. Accessed November 2, 2012.

7. George AP, De R. Review of temporal bone dissection teaching: how it was, is and will be. J Laryngol Otol. 2010;124:119-25.

DOI: https://doi.org/10.1017/S0022215109991617

8. Patnaik VVG. Editorial. J Anat Soc India. 2002;51(2):143-4.

DOI: https://doi.org/10.1590/S1415-790X2002000200001

9. Wiet GJ, Stredney D, Sessanna D, Bryan JA, Welling DB, Schmalbrock P. Virtual temporal bone dissection: an interactive surgical simulator. Otolaryngol Head and Neck Surg. 2002;127(1):79-83. DOI: https://doi.org/10.1067/mhn.2002.126588

10. Wiet GJ, Rastatter JC, Bapna S, Packer M, Stredney D, Welling DB. Training otologic surgical skills through simulation-moving toward validation:a pilot study and lessons learned. J Grad Med Educ. 2009;1:61-6. DOI: https://doi.org/10.4300/01.01.0010

11. Okada DM, de Sousa AM, Huertas RdeA, Suzuki FA. Surgical simulator for temporal bone dissection training. Braz J Otorhinolaryngol. 2010;76:575-8.

DOI: https://doi.org/10.1590/S1808-86942010000500007

12. Fried MP, Uribe JI, Sadough BB. The role of virtual reality in surgical training in otorhinolaryngology. Curr Opin Otolaryngol Head Neck Surg. 2007;15:163-9.

DOI: https://doi.org/10.1097/MOO.0b013e32814b0802 